Da ZHENG

English Department, Suffolk University

Boston, MA 02108, USA

dzheng@suffolk.edu

\title{
CREATIVE RE-CREATION IN CULTURAL MIGRATION
}

\section{Recommended Citation}

Zheng, Da. "Creative Re-creation in Cultural Migration". Metacritic Journal for $\begin{array}{lllll}\text { Comparative Studies } & \text { and } & \text { Theory }\end{array}$ https://doi.org/10.24193/mjcst.2017.3.02

\begin{abstract}
Lady Precious Stream by Shih-I Hsiung was the first successful West End play by a Chinese playwright. Based on a traditional Chinese opera but with many changes, the play had an enormous appeal to the modern audience in the West. This paper argues that the play is essentially an ingenious re-creation in which Hsiung has undertaken a combination of three roles: translating the original into English; adapting it to the English theatrical practice while maintaining the Chinese convention; and re-writing some of the details. Hsiung is thus able to keep the original cultural elements with sensitivity to the taste, convention, and ethical values of the targeted audience, transforming the ancient Chinese opera into a modern English-language play. Lady Precious Stream reveals the evolution and mutation of literary products that cross cultural and geographical boundaries as well as the significant role a writer may play in transcultural exchanges.
\end{abstract}

Key Words: Lady Precious Stream, Shih-I Hsiung, translation, transcultural exchange, Chinese drama

Lady Precious Stream (1934) by Shih-I Hsiung was a successful West End play by a Chinese playwright. Based on a traditional Peking opera, but with many changes, the play had an enormous appeal and ran approximately 900 shows, becoming the 
longest running show in London in 1937. It was then staged on Broadway in 1936, trailblazing as the first play written and directed by a Chinese.

Hsiung has been celebrated as the translator, adaptor, and playwright of the play ever since its publication. The play was said to be "the translation" of "a characteristic specimen of the average Chinese drama," and Hsiung was the "translator" (Bishop; Erkes 152). And it was said to be the result of an "extraordinary" adaptation of the "Eight Acts of the Wang Family," achieving a sense of unity with a firm "comic outline" (A Chinese Play). Some other critics, dazzled by the play that "dances with distinctive charm," simply identified it as an English-language play written by "a Chinese actor, who has a miraculous command of our language" (Chinese Satire). While all these terms seem to have offered a somewhat fair description, none of them, however, could be considered as an accurate definition by itself alone, due to partiality and limit. In my view, the play is essentially an ingenious re-creation for which Hsiung has undertaken a combination of all these three roles, namely translator, adaptor, and creator. Such an understanding, I believe, may not only help explain the secret of its success and popularity but also point out the importance of creative re-creation in cultural migration.

I would like to start with a short poem in the first act of Lady Precious Stream, because its evolvement in translation may serve as an illuminating example. The play itself begins with Prime Minister Wang Yun, who plans to celebrate the New Year's Day with his family in the garden. As snow is falling, the ambience enhances the joyous festive spirit. Hsieh Ping-kuei, the gardener of the Wang family, is asked to move a huge rock to the centre of the garden to serve as the table for the feast. $\mathrm{He}$ complies and accomplishes the task without much difficulty after several others have tried first but all failed. Hsieh is then asked to compose a poem to celebrate the occasion. Once more he complies and swiftly composes the following:

Wine brings a double cheer if snow be here, Snow takes a brighter white from song's delight.

Ah, but when cups abound, and song is sweet, 
And snow is falling round, the joy's complete. ${ }^{1}$

When Hsiung was working on the play Lady Precious Stream, he prepared a Chinese version of this poem and got it translated with the assistance of Thomas H. Silcock. Born in Chengdu, China in 1910, Silcock was the son of English missionaries Margaret and Harry Silcock. He moved back to England with the family in 1919. Both of his parents were active members in social and academic circles. His father Harry served as General Secretary of the Friends Foreign Mission Association and then as Secretary of the Universities' China Committee in 1932. Hsiung got acquainted with the family after he came to London and enrolled as a graduate student at London University. As for Silcock, he completed his high education at London University and then at Oxford University. He majored in economics and established a solid training in classics.

Through his mother Margaret's introduction, Silcock was asked to help render the Chinese poem in English. He completed the translation and titled the poem as Wine, Snow and Poetry. He told Hsiung, in a letter dated July 29, 1933, that he had tried to "capture the tone of the original." Since the poem was "somewhat unusual," he included two versions for Hsiung to consider. As he explained, one of them attempted to imitate the "rather short epigrammatic idiom of the Chinese," and the other, slightly longer, used the form of "an English drinking song" (Silcock).

No. 1:

Wine brings but little cheer till snow be here-

Snow, unless poets sing, a dismal thing.

But when the cups abound, the song's complete,

And snow is falling round, joy's full and sweet.

No. 2:

Oh wine can bring but little cheer

Until the days of snow be here,

And snow's at best a dismal thing.

${ }^{1}$ Shih-I Hsiung, Lady Precious Stream (London: Methuen, 1934), 21. Subsequent references to this work will be included in parenthesis in the text. 
Empty, unless the poet sing.

But when both wine and songs abound,

Where mellow hearts and poets meet,

And snow is falling, falling round,

Ah then our joy's complete. (Silcock)

Eventually, Hsiung selected the first version for use in the play with some noticeable minor yet significant alterations. The first two lines of the poem stress the importance of snow and poet's song. Silcock's rendition describes the status before the presence of snow and poet, making it a rather bleak and forlorn scene; Hsiung's version, however, offers a joyous picture with both snow and poet present. Words such as "little cheer" and "dismal" are substituted with "a double cheer," "a bright white," and "delight." Hence, the tone and mood of these two versions are strikingly different though the meaning essentially stays the same. Another significant change is the word "Ah" in line 3 of Hsiung's version. It serves as a pause, preparing the reader for the exclamation and appreciation of the ultimate consummation of joy when snow, wine, and poetry are simultaneously present.

Over two decades later, in 1956, the Chinese version of the play Lady Precious Dream was published in Hong Kong, and it contained the poem as follows:

Snow without wine bring but little cheer;

Wine without poems leaves us dull.

When cups abound, poems made, and snow falling,

The whole family together, the joy becomes complete. ${ }^{2}$

The poem follows Chinese classical poetic format: four lines, each with seven characters, all rhymed except the third line. Silcock's version appears faithful to this

\footnotetext{
${ }^{2}$ My translation. The poem is as follows:

有雪无酒不精神;

有酒无诗俗了人；

酒醉诗成天又雪；

阖家同庆十分春! (Hsiung, Wang Baochun 20)
} 
poem as far as the first two lines are concerned. In other words, this may have been, or at least very close to, the original version that both Silcock and Hsiung worked on in the 1930s. It was very likely that Hsiung, with the Western audience in mind, made those overt changes when he was rendering the final translation based on Silcock's rendition. ${ }^{3}$ In the meantime, the third and fourth lines of this Chinese poem markedly differ from either of the earlier versions.

To make the matter somewhat more intriguing, I would like to point out that Hsiung's poem can be traced to Snow Plum, a famous poem by Lu Meipo (卢梅坡) of the Song Dynasty (962-1279):

Plum flower without snow brings but little cheer;

Snow without poems leaves us dull.

When light dims, poems made, and snow falling,

Plum flower as the company, the joy becomes complete. 4

These two poems bear striking resemblances in syntactical structure, word choice, and rhetorical expressions. While Lu's poem focuses on the relationship among plum flower, snow, and poetry, Hsiung's on snow, wine, and poetry. Apparently, Hsiung has literally borrowed the first two lines, verbatim, substituting “梅” (plum flower) and “

3 The poem was later rendered into Chinese by Tao Xingzhi, a well-known educator and reformer in China. The following is Tao's translation, which does not follow the strict Chinese poetic form. Rather, it is like a free verse; like a song, with musical quality; and with the second and fourth lines rhymed.

对雪饮酒酒更香,

高歌一曲雪增辉。

但愿杯长满, 歌长好, 雪长飘,

欢乐极兮人忘归。(Tao 280)

Tao's translation is admirably faithfully creative. The second and fourth lines are rhymed, and the first two lines are accurate in terms of its meaning. However, the third and fourth lines depart from the original in format and content. Their literal meaning is the following: "But we wish cups always abound, Songs always sweet, and snow always round / Joy is complete and we linger on."

4 My translation. The original "Snow Plum" poem is as follows:

有梅无雪不精神,

有雪无诗俗了人。

日暮诗成天又雪,

与梅并作十分春。 
雪” (snow) of the first line with “雪” (snow) and “酒” (wine). The elimination of plum flower and introduction of wine should be underlined here. Plum flower, an important cultural element in China, has been one of the most favourable subjects in poetry and artworks for many centuries. Comparatively, plum flower is little known and generally not appreciated in the West.

On the other hand, wine, which is equally appreciated in both China and the West, is widely known for its cultural and literary associations. In both Greek and Roman mythology, there are gods of wine, i.e. Dionysus and Bacchus; likewise, Yi Di and Du Kang are two gods of wine worshipped in China. Ancient Greek poet Pindar sings, "Praise wine that is old, but praise the flowers of songs that are new." Li Bai (701-762), the "Great Poet-Saint" of the Tang Dynasty (618-907), loved good wine. If he were given a flagon of wine, he could compose 100 poems instantaneously. Therefore, the utilization of wine image in Hsiung's play makes perfect sense as it enables the poem to be easily relatable and acceptable to the readers in the West. In addition, Hsiung's poem makes a reference to the gathering of the Wang family, the poem fits perfectly the specific occasion in this case.

The intertextual influences and borrowing in this case could undoubtedly be an interesting subject for further discussion. For our purpose, however, I would just focus on how Hsiung has appropriated the original version and transformed that into a seemingly similar, yet entirely different new version, that is, the translation with adaptation and creative modifications. In fact, that is exactly what Hsiung has applied in his making of Lady Precious Stream: translating the original into English; adapting it to the English theatrical practice while maintaining the essential Chinese convention; and rearranging and re-writing details to make the story appropriate for the modern audience in the West. By so doing, Hsiung preserves the original cultural elements with sensitivity to the taste, convention, and ethical values of the targeted audience in the West, and the ancient opera from China is thus transformed into a modern English-language play.

The original Peking opera Wang Baochuan (王宝釧), also known as Wild Horse with Red Mane, was a love story about the maiden Wang Baochuan, who gave up high social status to marry Hsieh Pingkwei, a homeless beggar. Wang was the 
daughter of the prime minister. Treasuring the value of true love in her heart, she defied the convention of marrying the rich and noble, cut off her familial tie, and moved out to live with Hsieh in a cold and desolate cave. Shortly thereafter, Hsieh was conscribed to serve in the army to fight barbarians in the Western Regions. He was captured by the enemy, yet he survived and married Princess Daizhan. In the meantime, Wang lived in the cold cave alone, faithfully waiting for her husband's return. Eighteen years later, Hsieh came back home with his second wife Daizhan and reunited with Wang Baochuan.

Substantial formal changes have been made in Lady Precious Stream when Hsiung transformed the original into this new English-language modern play. The original play Wang Baochuan consisted of eight short acts. Traditionally, only one or two of those acts would be staged at one time on any night. Hsiung combined and condensed all eight acts, and reduced them to a four-act play, so that it could be played in two and a half hours.

Another major formal change is the elimination of singing, dancing, and acrobatic elements in the original play. In Peking opera, performers use a variety of acting techniques, including singing, acting, combat, and acrobatics as well as dialogue, which are stylized, symbolic, and suggestive. Speeches and songs in Peking opera are stylized, generally depending on the unique rhyme and rhythm patterns of the Chinese language, and they are nearly impossible to represent in English. Besides, speeches in Peking opera are musical, and songs are often accompanied by dance. Since Lady Precious Stream is in the English language, the tonal qualities, rhyme, rhythm, and couplet elements of Chinese cannot possibly be retained. Besides, singing and acrobatics require many years of training, skills that would be impossible for the theatrical artists in the West to obtain in a short amount of time. Therefore, Hsiung's decision to eliminate these elements and replace them with dialogues accompanied by some background music was practical and dramatic as it allowed the new play to be consistent with the theatrical practices in the West, familiar to the audience there (Zheng, Returns Home 34).

It is worth pointing out that some of the essential changes Hsiung made in the play helped ensure consistency, unity, and smooth flow of the story. Madame Wang's visit to her daughter in her dwelling, for example, was a famous act in Wang 
Baochuan, and the episode took place seventeen years after Hsieh left for the Western Regions. In Hsiung's play, however, it happens in the last part of Act II, approximately nine months after Hsieh's departure. This Act, which is set in the cave, includes Hsieh's conscription and departure as well as Madame Wang's visit. The change brings together all these details in the same act, concluding the first part of the story before moving on to the next act set in Western Regions eighteen years later. The drastic shift in time and space between the two acts appears perfectly natural in theatrical presentation on the stage.

Another prominent innovation by Hsiung is the feast on New Year's Day at the Wang family's garden in Act I. Wang Yun tells his wife that he plans to arrange a feast to celebrate the festival and enjoy the snow. He instructs his wife to persuade their youngest daughter "to consent to marry one of the young nobles whose suit I have approved." This lays the ground for the story to unfold. The garden scene, through the moving of the rock and composition of the snow poem, gives a wonderful introduction to the major characters. The reader perceives the physical strength and literary cultivation of Hsieh in contrast to the incompetence and ignorance of Precious Stream's two brothers-in-law. Besides, Precious Stream, who falls in love with Hsiesh because of his talent and integrity, is shown to be very different from her two sisters.

The translation of the text from Chinese into English reveals Hsiung's extraordinary mastery of both languages and cultural sensitivity. The play uses the main character's name for the title, rendered as Lady Precious Stream, with the last name omitted. It is a free translation that Hsiung proudly proclaimed to be far more satisfying and befitting. Even though many people have pointed out, even to Hsiung in person, that "stream" or 川 is a mistranslation or misrepresentation because the word 釧 (bracelet) in the original, though with the same pronunciation as chuan, has a radical of 金 (metal). At a banquet in Hong Kong in the 1950s, Hsiung defended his rendition with the following unequivocal explanation: "In Chinese, the word 川 (chuan) is far more elegant than 釧. In terms of the English translation, «bracelet» or «armlet» appears unrefined with two syllables, yet «stream» is monosyllabic and 
poetic" (Hsiung, Wang Baochuan 2)5. Hsiung was clearly not just attempting to find equivalent phrases or counterparts in the target language; he was instead weighing, among other factors, connotations, sounds, and cultural tradition.

There are many such instances in the new play. Take for example, in Act I, Wei reveals his ignorance through misuse of the word "perspiration" for "inspiration." The Chinese counterparts of these two words are 淋汗 (lin-han) and 灵感 (ling-gan) respectively.

Wei. I am rather sorry to say that I am not in the right mood for poetry now. I remember some poet said: "To write good poems, one needs perspiration!" It is very cold now, you see. We can't expect any perspiration until the summer comes.

Wang. Perspiration? You mean inspiration!

Wei. Oh, yes! Inspiration! (He wipes his forehead with his sleeves.) Not perspiration! Of course not perspiration! (18)

And in Act III, Princess Daizhan leads her troops in chasing Hsieh, who has secretively left for China. Upon their arrival at the third pass, Ma Ta and Kiang Hai, two aides-de-camp of the Princess, speak with General $\mathrm{Mu}$, the warden of the pass. Since $\mathrm{Mu}$ is elderly, he cannot hear words properly, so their conversation turns out to be difficult, frustrating, yet extraordinarily hilarious. The original Chinese text was as follows:

Kang: Please, Old Man.

$\mathrm{Mu}$ : Old man does not play fire ball.

Ma: Old General.

$\mathrm{Mu}$ : Old ginger is available at the market.

Ma: My King!

5 In fact, as Hsiung noted, the name of the play Lady Precious Stream had been invariably changed in other European countries for stage productions or publications. In Holland, for example, it became 綉 球緣 for the stage play, and the main character's name became 珠川 or Pearl Stream. And Lady Precious Stream's name changed to be 王春泉 in the Czech version and 王钻川. See Shih-I Hsiung, Bashi huiyi, 115. 
$\mathrm{Mu}$ : Rhubarb is available at the grocery store.

Ma: My Master!

$\mathrm{Mu}$ : Pork joint is available at the butcher's.

Ma: My Lord!

$\mathrm{Mu}$ : It is available at the fisher market. ${ }^{6}$

The phrases, such as 老将 (laojiang, old General) and 老姜 (laojiang, old ginger), 大 王 (dawang, My King) and 大黄 (dahuang, rhubarb), 主子 (zhuzi, My Master) and 肘子 (zhouzi, pork joint), are homophonous in Chinese, which caused misunderstanding and miscommunication. In Lady Precious Stream, the conversation is preserved, and the humour, resulting from repeated miscomprehension and non-sequitur in Mu's responses, is also beautifully retained. But note that Hsiung used "old moon," "kinsman," "mustard," "Heaven" instead, terms that are proper in the cultural context of the West yet perfectly (mis)matching the prompters:

Ma: Hey, my old man!

Mu: Old moon? We can't see the old moon until midnight.

Kiang: My old General!

Mu: Old ginger? Buy it at the market where vegetables are for sale.

Ma: My king!

Mu: There is no kinsman of yours in China.

Kiang: My master!

Mu: Mustard? Go to the grocery for it!

${ }^{6}$ My translation. The original is as follows:

江海：老头请呢！

莫老将军: 老头不玩火球。

马达: 老将!

莫老将军: 老姜到菜市买去。

马达: 大王!

莫老将军: 大黄药店买去。

马达: 主子!

莫老将军: 时子要到肉店里买去。

马达: 皇上!

莫老将军: 鱼摊上买。(Gan Sanguan) 


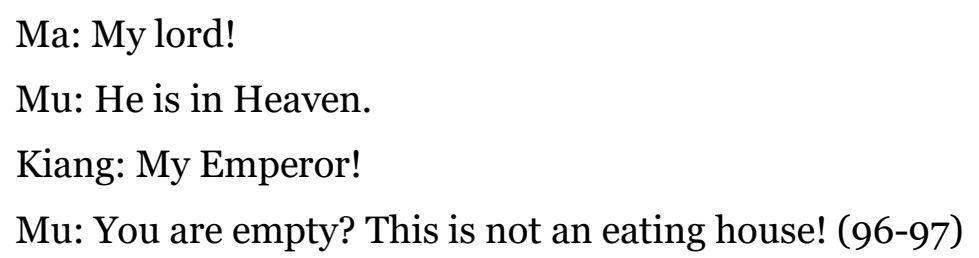

The original Peking opera Wang Baochuan contained some supernatural fantastic elements, which have been either altered or eliminated in Lady Precious Stream. The red-mane steed in the original play was initially a monster that attacked villagers. After being captured and subdued by Hsieh, the monster revealed its true form and became Hsieh's personal mount. In Lady Precious Stream, Hsieh sets out to eradicate the "monster with a red mane" that has been "devouring travellers in a wood." Eventually, it is discovered that the monster is a "tiger of enormous size," which Hsieh kills to protect people from further harm and danger (58).

In the original play, Hsieh was a homeless beggar that Wang Baochuan observed outside the family garden. As Hsieh was wrapped in a fiery aura, Wang presumed that this must be a man of super-eminence. Coincidentally the night before, she had dreamed of a red star falling in her bedroom, so she believed that the man in front of her must have been what the dream had prophesied. Hence, she fell in love with Hsieh at once. In some earlier versions, Hsieh was even said to be the reincarnation of the emperor's son, protected by Heaven (Chenying Shizhu 4). In Lady Precious Stream, Hsieh is introduced as the gardener of the Wang family. Endowed with extraordinary physical strength, he helps move an enormous rock to the centre of the garden for use as the feast table, and then composes a graceful poem about the snow, displaying his exquisite literary skills and taste. Hsieh is shown to be a decent and intelligent gentleman. Therefore, the succeeding love relationship between him and Precious Stream appears logical and convincing.

In the original play Wang Baochuan, the title character dropped an embroidered ball from a pavilion in the garden to the crowd gathering outside as a way of selecting her future husband. It was the God of Marriage who intercepted the ball and handed it over to Hsieh, the beggar. In Hsiung's play, the detail of the ball dropping is preserved but with a twist to turn that into a deliberate endeavour to defy social conventions: Precious Stream declares unequivocally that she is to take the case 
"into my own hands" (27). She tells Hsieh: "On the second of February it will be my sixteenth birthday, and I am going to marry the man who is hit by the embroidered ball which I shall throw down from a beautiful pavilion to be erected here" (27). Through her clever manoeuvring, Precious Stream manages to distract the crowd and then drops the ball, which lands in Hsieh's hands. Hence, it is neither a coincidence nor an intervention by the "will of God" (27). Rather, it is an outcome of human volition and endeavour. Precious Stream is intelligent, witty, and honourable, different from the character of Wang Baochuan in the original play, who was an embodiment of traditional Chinese feminine virtues of submissiveness and subordination (Zheng, Diaspora Literature 27).

These changes have brought about freshness and reduced the barriers between the past and present, the East and West. Hsiung was fully aware that some traditional cultural practices in China were not agreeable to the social values in the West and in fact not even acceptable to the Chinese in the 1930s. Therefore, it became critical to revise, remove, and even replace some of the details for the sake of logic and humanity.

Wei $\mathrm{Hu}$, a villain, was executed by Hsieh at the end of the original play, but in Lady Precious Stream he receives forty strokes instead as a punishment for his cruelty, embezzlement, and betrayal. The evil is thus denounced without invoking torture or death penalty.

The most important is probably the revision relating to Hsieh's bigamous relationship with Princess Daizhan. After being captured in the battle, Hsieh survived, married the Princess, and became the emperor of the Western Regions, where he stayed for eighteen years. He returned home near the end of the play and reunited with his wife Wang Baochuan, who happily welcome him and accepted Princess Daizhan as her "sister." Daizhan proposed that Wang Baochuan should remain as the wife while she herself could serve as the concubine, but Wang insisted that they should be equal and friendly like "two sisters" (Hui Longge).

The bigamous relationship would certainly be intolerable to many of the audiences in the West, and Hsiung made a creative revision in Lady Precious Stream. Hsieh is shown to be a man of moral integrity. During his captivity, he is caught in a dilemma: he is aware that the Princess is in love with him, yet he cannot openly 
reason with her or even reveal his marital status. He promises the Princess that he will marry her after his coronation in the future, which is a pretext for postponing the wedding. On the night before the coronation ceremony eighteen years later, he keeps toasting the Princess, and after she gets drunk, he escapes back to his own homeland. While the Princess remains a beautiful and courageous character, Hsieh and Precious Stream are shown to be virtuous, righteous, and admirable. The change dramatizes Hsieh's wisdom and loyalty to Precious Stream. It removes the bigamy detail in the original play, thus circumventing a thorny moral issue that could potentially provoke much fierce criticism and alienate the audience in the West (Zhang, Performing Transposition 85-87).

Prose descriptions at the beginning of each act is a unique feature that Hsiung has added to Lady Precious Stream. In Peking opera, no such detailed introduction has ever been provided since the reader, actor, and audience in China could easily follow because of their cultural knowledge and familiarity with the tradition. Hsiung's use of those lengthy introductions bears the influences of James Barrie, who is known for the excessive prose narratives in his plays. Hsiung was an admirer of Barrie, and he had translated many of Barrie's plays, including Peter Pan and The Admirable Crichton. He used the same technique for Lady Precious Stream, but the descriptions in that play not just serve to present the scenes, announce characters, or introduce stage setting; they provide a venue for Hsiung to introduce stage setting and Chinese theatrical tradition.

Lady Precious Stream begins with the following that introduces the stage scene, the concept of Property Men, and minimalist Chinese stage setting:

Let it be clearly understood that this unfurnished stage represents the scene of the picturesque garden of the Prime Minister Wang Yun.

A pole with some branches and leaves attached and fastened to a chair is placed on the right by a man in black, and an odd-looking table is placed on the left by another in similar dress. They are the PROPERTY MEN of the Chinese stage, and their ministrations are supposed to be unseen by the audience. So we must bear in mind that trees (represented by the pole fastened to the chair) and rocks (represented by the oddlooking table) have been scattered here and there for some time by the invisible hands 
of Nature; and further, though these two men are still standing at the back, we must consider the stage to be empty. (1)

Likewise, the following is an excerpt from the introduction at the beginning of Act III.

The stage represents the magnificent court of His Majesty the KING OF THE WESTERN REGIONS. Probably they have very queer furniture and very strange decorations. Indeed, we would be quite at a loss to prepare the properties of his scene had we not had the advantage of being able to leave the audience to furnish them according to their own imagination. (78)

Its tone is very Barriesque, that is, both meditative in marvelling at the "strange decorations" of the Western Regions and sympathetic with the audience who are likely puzzled. Hsiung uses the pronoun "we" to suggest a collective voice that includes producer, actor, and playwright. The "we" here is not entirely antithetic to the audience. Instead, it is a sympathetic and collaborative relationship. It encourages and directs the audience to "furnish" the details "according to their own imagination," indicating that it is the correct way to view and appreciate this minimalist setting of Chinese theatrical convention.

It should be pointed out that, when staged in London and other parts of the world outside China, Lady Precious Stream includes the character Honourable Reader on the cast. Honourable Reader narrates the connecting sequences of events or scene changes, explains the symbolic representations of the stage, and comments on some essential technical and theatrical aspects for the Western audiences. When Mei Lanfang toured the US in 1930, the troupe arranged to have an English-speaking commentator introduce the general techniques and explain the plot of the play before the rise of the curtain. With this additional information, the audiences could grasp the meaning and better appreciate the play. Hsiung took a step further by creating the character Honourable Reader and assigned her a prominent role in Lady Precious Stream: The Honourable Reader appeared on stage before each act, narrating the connecting sequences of events or scene changes and explaining the symbolic representations of the stage; and she concluded the play with a humorous 
observation, poking fun at the theatrical giants Eugene O'Neil and George Bernard Shaw: "The Chinese play is no longer than a Western one. They are rarely as long as Strange Interlude, and never longer than Back to Methuselah ("Lady Precious Stream").7

One of the most memorable part is in the beginning of Act III:

We are coming to a strange land known as the "Western Regions." It is believed that the customs here are exactly opposite to those of China. For instance, the women here wear long gowns, whilst the men wear short coats and have their trousers showing. Their appearance, too, is unusual. All, male and female, have red hair, green eyes, prominent noses, and hairy hands. To most people these things seem to be quite unbelievable, and the idea of the existence of such a country with such inhabitants seems to be as absurd as believing there is a race which laughs when sad and weeps when happy, or walks with hands and works with feet! Yet the books of wise men tell us that the country of the Western Regions does exist, and now we come to have actual experience of it. (78)

The descriptions of the costumes, features, and customs of the people of the Western Regions in the passage above are entirely Hsiung's invention. There seem to be some overt similarities between the people in Western Regions and those in the West. These strange similarities could strike the audience as their own reflection and quickly cause a certain degree of discomfort and bewilderment. While the audience are intrigued with the images of the Western Regions, they instantaneously realize that these are somewhat familiar images of themselves. They have become the object of observation. Yet, all those familiar phenomena suddenly dissipate and turn "absurd", since people in the Western Regions laugh when sad and weep when happy. A familiar world suddenly becomes defamiliarized, conventional wisdom is challenged, and the Western Regions, which seems to have been accepted like a local setting, suddenly becomes as distant as China. The double vision and impressions, between the contemporaneous West and the ancient Western Regions, challenge the audience's

\footnotetext{
7 Strange Interlude, by Eugene O'Neill, was first produced on Broadway in 1928. It ran over four hours, and sometimes it was produced with a dinner break or on consecutive evenings. Likewise, Back to Methuselah, a comedy by George Bernard Shaw, could hardly be played at full length because of its enormous size.
} 
perception and enhance the artistic power of the translation (Zheng, Diaspora Literature 30).

In the "Introduction" to the Lady Precious Stream, Hsiung writes:

In this play I have not attempted in the least to alter anything. The following pages present a typical play exactly as produced on a Chinese stage. It is every inch a Chinese play except the language, which, as far as my very limited English allows, I have interpreted as satisfactorily as I can. (xvii) [Italics mine]

The English word "translate" came from Latin translatus, which is the past participle of transferre, meaning "to transfer." Translation, with that origin, means transposing the meaning from one nation or culture to another nation or culture. Interestingly, in his explanation Hsiung states, "I have interpreted as satisfactorily as I can." He uses the word "interpret," which carries an equivalent meaning of translation and is often interchangeable with "translate." Nevertheless, the word "interpret" may also denote some additional meaning, such as "explicate" or "expound." Hsiung was fully aware of the subtle differences between "translation" and "interpretation" when he made that claim. His choice of the word "interpret" was deliberate and meaningful.

Translation is indeed a form of interpretation. Critics, such as George Steiner, Susan Bassnett, and David Damrosch among others, have underlined the critical relationship between the two, or the role of interpretation throughout the process of translation. When selecting a phrase or deliberating over the syntactical structure in the target language, the translator is inevitably engaged in interpretation (Bassnett 2122). Even any thorough reading of a classical text of one's own language and literature is in fact "a modified act of interpretation" (Steiner 17).

Needless to say, being culturally and linguistically sensitive to the target language and socio-cultural setting is the key to a good translation. Otherwise, any attempt to meticulously convey the original through "the purer language," as David Damrosch has shown, would become "hardly readable at all" (157). In his illustration of the degree of freedom the translator enjoys in translation, Damrosch cites the English-language translation of Onegin and the Russian-language translation of Alice in Wonderland, both by Vladimir Nabokov. In Onegin, one-seventh of the edition's 
1,400 pages is the poem while the rest is Nabokov's notes, cumbersome and totally esoteric to the ordinary reader though unquestionably the "best part of his edition."

On the other hand, Nabokov's translation of Alice in Wonderland is surprisingly delightful with Russian equivalents for Lewis Carroll's seemingly untranslatable chains of puns. Nabokov was thinking "in terms of world literature" rather than re-creating the Victorian England. He did not attempt to convey the flavour of life in Victorian England; instead, he strived to "see Carroll's uncanny wonderland through a Russian lens" (157). Between the two translations, Alice in Wonderland is apparently a more successful product in terms of its circulation and reception in the international literary market. Likewise, Lady Precious Stream is by no means an ordinary word-for-word translation: it is a translation with much interpretation; a faithful representation of the original with explication and revisions; and a recreation aimed for broad admiration and appreciation in the twentieth century West.

With its theatrical success, Lady Precious Stream has enjoyed broad transcultural circulations in the world. It has left us with some valuable lessons to contemplate. Cultures are in flux. They travel and cross all kinds of borders, national, geographical, spatial, ideological, and socio-political. As Wolfgang Welsch has indicated, global migration and communication have increasingly turned modern cultural conditions into transcultural, characterized as "mixes and permeations," beyond mere intercultural and multicultural relations as in the earlier centuries (197). It is often difficult to describe or even identify something as entirely foreign or our own in this new transcultural environment (Ascari 7). Nevertheless, for cultural products to become popular and acceptable, innovative adaptation and creative alterations as well as cultural sensitivity are essential. What is needed, in short, is creative re-creation in transcultural communications, as exemplified in Lady Precious Stream.

\section{References}

"A Chinese Play." Times Literacy Supplement 12 July 1934.

Ascari, Maurizio. Literature of the Global Age. Jefferson: McFarland, 2011.

Bassnett, Susan. Translation Studies, rev. ed. London: Routledge, 1991. 
Bishop, George W. "The Malvern Festival: A Theatrical League of Nations," Sunday Times 29 July 1934.

Chenying Shizhu, ed. Hongzong liema [Red-mane Steed], vol. 2. Shanghai: Xiyin Press, 1933.

“Chinese Satire," Daily Herald 19 July 1934.

Damrosch, David. What Is World Literature? Princeton: Princeton UP, 2003.

Erkes, Eduard. “Lady Precious Stream.” Artibus Asiae Vol. 6, No. 1/2 (1936) 152.

Gan Sanguan (赶三关) http://scripts.xikao.com/plays/play.php?id=01012011.

Accessed 9 September 2010.

Hsiung, Shih-I. Bashi huiyi (Memoirs in the 8os). Edited by Chen Zishan. Beijing: Haitun Press, 2010.

Hsiung, Shih-I. Lady Precious Stream. London: Methuen, 1934.

Hsiung, Shih-I. Wang Baochuan (王宝川). Hong Kong: Drama Research Press, c. 1956.

Hui Longge (回龙阁) http://scripts.xikao.com/plays/play.php?id=01016007.

Accessed 9 September 2010.

"Lady Precious Stream Has a Living Heroine," N.P., c. 1936.

Silcock, Thomas H. to Shih-I Hsiung, 29 July 1933. Hsiung Family Collection.

Steiner, George. After Babel. NY: Oxford University Press, 1975.

Tao, Xingzhi. Education for Life. Beijing: Foreign Language Teaching and Research Press, 2012.

Welsch, Wolfgang. "Transculturality-The Puzzling Form of Cultures Today," in Spaces of Culture: City, Nation, World, eds. Mike Featherstone and Scott Lash. London: Sage, 1999.

Zheng, Da. "Lady Precious Stream, Diaspora Literature, and Cultural Interpretation." In eds. Kwok-kan Tam and Kelly Kar-yue Chan. Culture in Translation: Reception of Chinese Literature in Comparative Perspective (Hong Kong: Open University of Hong Kong Press, 2012), 19-32.

Zheng, Da. "Lady Precious Stream Returns Home." Journal of the Royal Asiatic Society China 76:1 (August 2016) 19-39. 
METACRITIC JOURNAL FOR COMPARATIVE STUDIES AND THEORY 3.1

Zheng, Da."Performing Transposition: Lady Precious Stream on Broadway." New England Theatre Journal 26 (2015), 83-102. 